\title{
LOS CÍRCULOS DE LA MEMORIA: EL CASO DEL URUGUAYO HENRY ENGLER
}

\author{
POR \\ GiovanNa URDANGaRAín \\ Pacific Lutheran University
}

Cuando salí de la cárcel fui a buscar el lugar donde habiamos pescado con mi abuelo. El arroyo había cambiado de curso. [...] El lugar [...] habia desaparecido...entonces eso a mí me produjo un poco la sensación de que lo que uno busca del pasado es dificil de reencontrarlo.

Henry Engler, El Círculo

A treinta años de la dictadura (1973-1985), Uruguay continúa negociando la inclusión de voces diversas en la configuración de su memoria social. Documentales, novelas y proyectos testimoniales de índole individual y colectiva ofrecen un corpus en expansión que demanda una valoración crítica e interdisciplinaria. ${ }^{1}$ Como parte de la producción cultural vinculada a la dictadura y sus efectos, se distinguen proyectos testimoniales definidos en torno de la categoría género, trabajos delimitados en función de una experiencia particular tal como lo fue la vida en prisión y la literatura surgida de dicha experiencia así como la labor de extensión cultural desplegada a partir del Museo de la Memoria (MUME, Montevideo, fundado en el 2007). ${ }^{2}$

Si la configuración de la memoria social uruguaya respecto de la "década infame" implica, como para todos los países que vivieron la represión del llamado Plan Cóndor, la incorporación de historias individuales que hagan públicas las diversas aristas de lo vivido en dicho periodo u originadas a raíz del mismo, un desafío adicional que enfrenta dicho proceso es el de superar los obstáculos derivados de lo que se percibe, aun dentro del movimiento de gestión por la memoria social, como urgente, vergonzoso, débil o censurable. Es así que ciertas experiencias del pasado, ligadas a la victimización a manos

1 Para una valoración amplia de la producción cultural uruguaya generada entre 1985 y 2005, ver el libro de Gerardo Caetano 20 años de democracia (2005).

2 Cabe especial mención al estudio historiográfico exhaustivo realizado en este campo por Alfredo Alzugarat, quien aborda más de setenta autores y cuarenta y cuatro obras producidas tanto dentro de la prisión como a partir de esa experiencia. 
del terrorismo de Estado, logran un espacio de representación y se convierten en objeto de reflexión colectiva en función no sólo de la receptividad social que haga viable su concreción pública y material, sino también de las dinámicas de disputa que definen dicho proceso. Si bien la represión desplegada por el Plan Cóndor conllevó para todos los países cono-sureños similitudes en las tácticas utilizadas, la constitución misma de los sectores de oposición reprimidos en cada país tuvo un perfil propio, lo que comportó consecuencias igualmente diversas. ${ }^{3}$ Asimismo, es posible identificar variantes en la prevalencia de ciertas tácticas represivas ejercidas por los regímenes dictatoriales de la región, diferencias que muchas veces por razones históricas o de signo ambiguo, han alcanzado visibilidad pública tardíamente o esperan aún el momento de ser analizadas. ${ }^{4}$

En relación con Uruguay y en respuesta a la pregunta: “¿Qué experiencia de violencia infligida al país durante la dictadura que aún no se ha abordado, considera imperativo que se discuta y se analice?", Elbio Ferrario (director del Museo de la Memoria, agosto de 2010) señaló la de la tortura. ${ }^{5}$ Situada en el espacio perturbador de la victimización y sujeta a valoraciones de corte ético, la tortura y su representación fluctúan entre un espacio que amenaza con relegar a las víctimas al estatus de pasividad o derrota o por el contrario, se materializan en una imagen heroica que dificulta cuando no imposibilita,

3 Ver "Análisis en clave comparada", capítulo 5 del estudio de Luis Roniger y Mario Sznajder.

4 Es el caso por ejemplo del abuso sexual como forma específica de tortura la cual en relación con lo vivido por las mujeres chilenas se hizo público en 2005, en Uruguay en 2010 y en 2012, en Argentina, su reconocimiento dio lugar a la primera condena por violencia sexual.

5 La entrevista a Ferrario fue realizada en Montevideo, en el contexto de una serie de encuentros con ex presas políticas, quienes generosamente respondieron a varias interrogantes relacionadas con el estado del proceso de configuración de memoria social en el país. A continuación incluyo la transcripción completa de la respuesta de Ferrario a la pregunta citada: "El tema de la tortura. Ha estado puesto el énfasis en el tema de los desaparecidos que condensan el horror del terrorismo de estado, [...] pero el tema de la tortura ha quedado como relegado. [Eso se ha dado] primero porque hubo todo un periodo de desmemoria grande en los primeros gobiernos de derecha y segundo, porque fue tanto el énfasis en el tema de los desaparecidos, hacer conciencia sobre eso que se negaba también, que el otro tema quedó como perdido. Hay una responsabilidad de todos los actores sociales, de todos nosotros en haber permitido que eso sucediera cuando en nuestro país lo masivo fue la tortura. Si en Argentina lo masivo fue la desaparición forzada, en Uruguay lo masivo fue la tortura y sin embargo, todavía es un tema que está trabajado en forma pobre. No hay una conciencia de eso, de que lo masivo fue la tortura en Uruguay, de cantidad de gente que no sabés cuánta fue. Tenemos registro de cerca de 6.000 presos políticos en las cárceles, en las cárceles más renombradas [...] pero después hay toda otra gente que ha pasado por cuarteles, por comisarías, incluso a veces por poco tiempo, $[\ldots]$ que también fue torturada y que no tenemos un registro claro, una cuantificación clara de cuánta es pero sí hay la noción de que a nivel de la población es el país que tuvo más presos y que a nivel de torturados debe ser también el país que tuvo más torturados. No es un tema que se haya trabajado, incluso hay cierta responsabilidad de las organizaciones politicas de izquierda de haberlo dejado. Incluso hay testimonios, entrevistas, declaraciones de algunos militantes que dicen: ya sabíamos en lo que nos metíamos, ya sabíamos que eso era parte de la lucha; pero eso afecta el hoy y de cualquier modo, no tenés que aceptar nunca que la tortura es una cosa normal, no lo es, no puede serlo nunca" (énfasis mío). 
la identificación entre lectores/espectadores y testimoniantes. Al mismo tiempo, las responsabilidades éticas inherentes a la representación estética de esta experiencia así como las implicaciones sociales y políticas que dicha representación conlleva han sido ampliamente discutidas en el campo académico. ${ }^{6}$

En el marco de una reflexión sobre el pasado para interpretar el presente del país, consideraciones como la que acabo de citar nos recuerdan que reflexiones sobre la tortura y la resistencia se vuelven cruciales. Desde ese marco me aproximo al documental uruguayo El Círculo, de José Pedro Charlo y Aldo Garay (2008). Se trata de la reconstrucción de la historia de Henry Engler, ex dirigente tupamaro y ex rehén de la dictadura uruguaya durante trece años quien sufriera confinamiento individual en condiciones infrahumanas y cuya experiencia de la violencia lo condujera a la locura. ${ }^{7}$ En la reconstrucción cinematográfica de su historia, Engler transita la memoria a través de rutas paralelas. Por un lado, revisita sitios y fechas ligados a la violencia experimentada en el pasado. Por otro, reflexiona sobre las estrategias de supervivencia desplegadas. Es en ese sentido, un doble proyecto que se constituye en objeto de estudio compartido tanto por los estudios de memoria como por los de trauma.

Cabe mencionar dos estudios sobre El Círculo publicados recientemente. El primero, de Jorge Ruffinelli, lo sitúa partiendo de un contexto latinoamericano amplio (el corpus fílmico creado a partir de los años 90) al que define en términos del tema central de la identidad explicando la prevalencia de dicho tema a la luz de dos fenómenos: "[...] el de la modernización técnica y artística del cine y el del logro de una autonomía respecto de los intereses que monopolizaron y definieron la industria hasta los años 60" (60). Superada la ilusión de interpretar al documental como reconstrucción objetiva de la realidad social que constituye su referente, Ruffinelli señala en lo que llama el "documental moderno" una creciente subjetivización del documentalista, que se manifiesta en el hecho de que el Otro antes narrado desde una óptica eurocentrista es ahora o bien él mismo o bien un sujeto en quien el cineasta, por lazos de índole histórica, cultural y personal, reconoce como su igual. Como consecuencia, lo autobiográfico prevalece (61). La tesis de Ruffinelli propone por un lado, que el "moderno documentalista" es el nuevo Otro que reflexiona sobre sí mismo y por otro, que el corpus al que se refiere conlleva una recuperación de la identidad cultural. Al establecer una genealogía para el proyecto de José Pedro Charlo y Aldo Garay (el corpus documental uruguayo como esencialmente político desde sus inicios), Rufinelli “sutura" la narración de la trayectoria de la producción fílmica uruguaya pre y posdictadura permitiendo una identificación

6 Ver Taylor, "Disappearing Bodies: Writing Torture and Torture as Writing" (139-182) y Scarry, "The Structure of Torture: The Conversion of Real Pain into the Fiction of Power" (60-160).

7 Ver el estudio de Ruiz sobre el primer trabajo que da cuenta de la misma experiencia vivida por mujeres (2012).

Revista Iberoamericana, Vol. LXXXI, Núm. 251, Abril-Junio 2015, 435-447 ISSN 0034-9631 (Impreso)

ISSN 2154-4794 (Electrónico) 
eficaz de elementos presentes en la producción reciente que no restringe su interpretación al periodo dictatorial, muchas veces conceptualizado como fractura irrevocable.

Si la voluntad de narrar la realidad latinoamericana, con objetivo descolonizador, constituía un objetivo primordial del llamado Tercer Cine, la diferencia respecto de la producción reciente, en términos estructurales y retóricos, estaría dada por el carácter individual de las historias recreadas en el corpus reciente. Del sujeto-símbolo de una realidad colectiva presentado en el Tercer Cine pasamos al sujeto-testimoniante de una historia individual, el que contribuye a la configuración de una historia colectiva que se acepta como difícil cuando no imposible de ser narrada en su totalidad sin recurrir a esas micro-visiones del pasado.

Por su parte, el análisis de David Martin-Jones y María Soledad Montañez postula la funcionalidad museística virtual que cumple El Círculo e identifica en el mismo estrategias técnicas específicas para representar espacios en el Uruguay de hoy como intentos de recuperar el pasado. De este modo, si bien los autores definen la índole de dicho proceso como de carácter individual, el efecto final sería el de completar los "huecos" en la narración del pasado nacional, de modo de contribuir a la configuración más completa de la historia colectiva. Al "leer" los documentales vis à vis respecto de los museos de memoria construidos en Argentina y Uruguay en el periodo analizado, dicho artículo implícitamente inviste a los primeros con el estatus de documento y remite al campo de estudios de memoria.

El Círculo como proyecto es en efecto un símbolo de la intersección de lo mnemónico y lo traumático. En su estudio sobre la genealogía del trauma, Ruth Leys demuestra que sobrepasada la instancia de violencia, se advierten dos tipos esenciales de trauma: uno internalizado que condena a la víctima a repetir la violencia sufrida y uno exteriorizado, que permite la denuncia. Paralelamente, las aproximaciones teóricas que abordan lo traumático se dividen en dos tendencias: mimética y antimimética. La primera nos plantea que la experiencia traumática condena a quien la vive a un destino de repetición hipnótica, a través de la cual el trauma se revive y se actúa, revelando así la incapacidad humana para incorporarlo a un sistema de representación y en última instancia, a la memoria misma. Esta forma de leer el trauma, asimismo, registra una instancia de identificación entre víctima y victimario que negativamente culmina por dirigir los sentimientos de destrucción y rechazo por la violencia, hacia la víctima misma. Inmovilizada en el acto de imitar para poder entender el trauma, la víctima queda incapacitada de testificar el acto de violencia que la tuvo por protagonista. La teoría anti-mimética por su parte, es más auspiciosa que la anterior, en el sentido de que al rechazar la noción de inmersión inmovilizadora de la víctima en el episodio traumático instala la posibilidad de pensar en un testimonio que se articule desde la víctima misma y en una identificación de la violencia como hecho esencialmente externo que "agrede" a un sujeto absolutamente formado. La posibilidad de la identificación con el victimario se excluye y al situar a la víctima fuera del acto de violencia se la concibe como capacitada para denunciar.

Revista Iberoamericana, Vol. LXXXI, Núm. 251, Abril-Junio 2015, 435-447 ISSN 0034-9631 (Impreso)

ISSN 2154-4794 (Electrónico) 
Eliminado el destino de repetición, se elimina la perturbadora idea de la complicidad (298-99).

Tanto Engler como el documental que lo tiene por protagonista pueden ser entendidos en el marco de lo que la socióloga argentina Elizabeth Jelin ha denominado "los trabajos de la memoria", entendiendo por esto una conceptualización de la memoria definida en términos de su instrumentalidad para el cambio social. Como nos recuerda Jelin, es necesario discriminar las instancias en que la memoria invade el presente y frente a cuya intrusión el sujeto y la sociedad que recuerdan permanecen atrapados en el pasado, de las gestiones a través de las cuales esa memoria se incorpora al presente, operando como agente de transformación a nivel social (5). Ambas dimensiones ejemplifican lo que psicoanalíticamente se ha concebido como un proceso de superación de una vivencia traumática, iniciado por la ritualista repetición del evento y la eventual superación del mismo a través del acto de interpretación. Como agentes sociales partícipes de la lucha por la memoria del pasado en Uruguay, Engler y los documentalistas José Pedro Charlo y Aldo Garay llegan a su audiencia investidos con un estatus específico: el que Jelin identifica como gestor mnemónico, es decir, una persona "[...] comprometida en mantener y promover una atención política y social activamente sostenida a su proyecto" (34). No hay que olvidar que el 2009 (año siguiente a la salida del documental que nos ocupa) marcaría en Uruguay una nueva instancia crucial para decidir vía referéndum la anulación de la llamada Ley de Caducidad. ${ }^{8}$ En ese sentido, las tensiones y ansiedades por persuadir a la sociedad uruguaya de la relevancia de volver a reflexionar sobre los temas presentados en El Círculo así como a instar a la acción social definían el escenario político nacional. Si bien la campaña por la anulación de la ley se lanzó en mayo del 2009, fue en mayo del 2007 que se comenzó la recolección de firmas para habilitar la consulta popular. Cabe mencionar que en el 2009 en Montevideo se publicó un libro titulado también El Círculo. Los tres autores (los directores de la película junto con la historiadora y cineasta Virginia Martínez) recuperaron en el libro material que no fue incluido en la versión final del documental (segmentos de entrevistas, cartas y fotografías). En el prólogo de dicho libro se elabora sobre la génesis del proyecto fílmico explicando que el interés de José Pedro Charlo en contar la historia de Engler surgió cuando "En febrero del 2004 la revista Caras y Caretas publicó un artículo que tenía un título sorprendente: "un Tupamaro hacia el Premio Nóbel"” (7). A partir de la noticia que circuló extensamente en el país durante ese mes y que Engler desmintió

8 Dicha ley garantizó la amnistía a los militares implicados en violaciones a los Derechos Humanos cometidas dentro del territorio nacional hasta el $1^{\circ}$ de marzo de 1985 . Constituyó asimismo uno de los puntos clave en torno a los que se firmó el Pacto del Club Naval (1984), clausurando las negociaciones que marcaron la transición a la democracia. En 1989, los uruguayos se manifestaron también por referéndum sobre la anulación de la ley (el 56.6\% del electorado decidió ratificarla) y en noviembre del 2009, la ciudadanía se expidió de la misma forma pero esta vez con el apoyo de un 53\% de los votantes.

Revista Iberoamericana, Vol. LXXXI, Núm. 251, Abril-Junio 2015, 435-447 ISSN 0034-9631 (Impreso)

ISSN 2154-4794 (Electrónico) 
(cosa que hace también en la película) se generó el proyecto de llevar a la pantalla la historia del ex guerrillero uruguayo, hoy neurólogo especialista en la investigación de la enfermedad de Alzheimer. La propuesta del documental presentada a FONA ganó el premio en su categoría en el 2005 y la recaudación de fondos para su concreción insumió dos años. Virginia Martínez afirma que en la propuesta "[...] se advierte que desde el origen del proyecto los directores sabían qué estructura narrativa y qué tono querían para el film" (8). De modo que cuando hablo de la función de gestión mnemónica para el documental no sugiero que haya sido la voluntad de los involucrados en su realización operar en el contexto social uruguayo en los términos en que Jelin habla de la gestión por la memoria. Sugiero, sin embargo, que la instancia histórico-política en que el filme llega al público uruguayo le asigna un carácter instrumental en ese sentido. Es claro que El Círculo, al abordar más explícitamente la tortura, un tema que como Ferrario señalaba, había sido injustamente soslayado, se inserta en ese diálogo/disputa social constituido por los diversos discursos de memoria. Del mismo modo, otros trabajos en el terreno de la literatura testimonial, específicamente carcelaria, se publican durante este periodo abordando la tarea de representar y provocar a la reflexión sobre la tortura ocurrida en el país. ${ }^{9}$

Representar la vivencia de tortura de una figura icónica del Movimiento de Liberación Nacional como la que representaba Engler suponía lidiar con la dificultad de representar el dolor y al mismo tiempo, documentar los mecanismos de supervivencia de un modo tal que dieran cuenta efectiva del trauma sin dejar al protagonista atrapado en el estatus de víctima. Si el tono del documental construye una visión fundamentalmente épica del sobreviviente se corre el riesgo de crear una distancia tal respecto del espectador que impida la acción del receptor del mensaje en lugar de promoverla. ${ }^{10} \mathrm{Si}$ por el contrario, se presenta al sobreviviente como inmovilizado en el espacio del dolor y en la categoría de víctima se incurre en la invisibilización de la resistencia ejercida, algo que iría en contra de la realidad misma que revela el documental: Engler y otros rehenes fueron eficaces en sus diferentes prácticas de resistir. Este dilema se revela formalmente en la multiplicidad de estilos documentales a los que adhiere El Círculo.

Teniendo en cuenta que el cine crea significado a partir de múltiples dimensiones más allá de la exclusivamente verbal, es necesario considerar el estilo y las técnicas empleadas en la representación sobre las que se erige. En su libro Introduction to Documentary, Bill Nichols señala que la eficacia de persuadir sobre el caso que presenta

9 Tanto el proyecto de Luis Fourcade (De bigote p'arriba, 2006) como el de Álvaro Rodríguez (Los desastres de la cana, 2007) hacen visibles textualmente las tensiones derivadas de representar el dolor y su superación.

${ }^{10}$ Ver Kimberly Nance (Can Literature...), quien en su aproximación al género testimonial, analiza especialmente las estrategias retóricas que facilitan o impiden la convocatoria a una acción social por parte del lector.

Revista Iberoamericana, Vol. LXXXI, Núm. 251, Abril-Junio 2015, 435-447 ISSN 0034-9631 (Impreso)

ISSN 2154-4794 (Electrónico) 
un proyecto documental implica cinco decisiones técnicas en términos de su dimensión retórica. Las dos primeras se vinculan con lo específicamente técnico: la edición del material filmado (cortes y yuxtaposición de escenas, selección de marcos y composición de las tomas) y la dimensión del sonido (naturaleza del mismo, incorporación de un narrador en off, yuxtaposición del mismo a la imagen o no). Las tres últimas decisiones se alinean en torno de la función narrativa que cumple el género: selección de una cronología (linear o determinada por episodios que funcionen como evidencia del concepto central sobre el que nos persuade el documental), uso o no de material fílmico externo al documental (fotografías, recortes de periódico, otras filmaciones) y finalmente modalidad de representación en la que se apoya para organizar el material: expositivo, poético, observacional, participativo, reflexivo o performativo (46). Si bien cada una de estas modalidades ha tenido prevalencia en distintos momentos del siglo XX, las dos primeras caracterizan la cinematografía documental de los años veinte, la tercera y la cuarta dominan la década de los sesenta mientras que las dos últimas signan la producción de los ochenta (Nichols 138), El Círculo despliega rasgos de todas ellas.

Dicha hibridez estilística revela el proceso inestable de deconstrucción de la configuración binaria del sobreviviente como víctima o como héroe y paralelamente, impide que la audiencia quede relegada a una posición de voyeur, admirador de la heroicidad o simple testigo del dolor representado. Al optar por la combinación de rasgos de las seis modalidades antedichas, el filme evade la rigidez de una definición unívoca de su propósito, función y relación que establece con los espectadores. Existe un énfasis en la dimensión tonal (establecida a través de la música y los silencios presentes en momentos de mayor dramatismo) así como una prevalencia de lo evocativo que lo emparentan con las modalidades poética y performativa respectivamente. La persistente opción por los grandes planos generales (de paisajes bucólicos tanto en Suecia como en Uruguay) se alinean con este estilo enfatizando la dimensión subjetiva de dos modos diferentes. Por un lado, estas tomas contrastan con la brutalidad ocurrida en esos mismos sitios y de la que la naturaleza no muestra huellas (los atardeceres y el campo que recorre durante el viaje a Uruguay). Por otro, enfatizan la paz alcanzada por Engler (su casa en Suecia, las sesiones de pintura a las que dedica su tiempo libre). También se yuxtaponen los estilos expositivo y observacional; el primero se verifica en la utilización del recurso de los narradores en off, voz de autoridad que guía la trayectoria narrativa a la que se invita a participar al espectador, pero que frecuentemente no coincide con la imagen que se proyecta. De este modo, nos vemos forzados a acompañar la trayectoria mnemónica de Engler al tiempo que vemos el presente. A través de este mecanismo se recrea la escisión inexorable entre el pasado que existe en su recuerdo y al que solamente podemos acceder por medio de su narración. Como ejemplo de esto cabe considerar el epígrafe que enmarca este ensayo y que en la película se superpone a una toma que enfrenta a Engler con el río, destacando la irreductible incongruencia entre la realidad geográfica

Revista Iberoamericana, Vol. LXXXI, Núm. 251, Abril-Junio 2015, 435-447 ISSN 0034-9631 (Impreso)

ISSN 2154-4794 (Electrónico) 
presente y el recuerdo de una realidad geográfica perdida. Otro ejemplo lo constituye la escena en que Engler se reencuentra con un ex compañero del movimiento y visitan el bar en donde ambos fueron capturados en 1972, hoy consultorio veterinario. Al intentar reconstruir la captura, las dudas que surgen en cuanto a la ubicación de los sujetos y el orden de los acontecimientos así como la evidencia de que cada uno de ellos sólo puede recordar parte de lo ocurrido destacan el carácter suplementario que cada versión tiene respecto de la otra. En otros casos, aún cuando el lugar que recuerda existe hoy, como el aljibe adonde era conducido como sitio de "recreo" en el Cuartel de Durazno, no le es posible reconstruir ni mental ni físicamente el camino que lo llevaba allí debido a las vendas que le cubrían los ojos. Esto resulta en la imposibilidad de crear un "mapa" que reconstruya visualmente esos recuerdos. Los espectadores, por su parte, solamente pueden ver lo que la cámara muestra hoy, sitios que divorciados del discurso de Engler, resultan insuficientes para contar la historia.

El estilo observacional, por su parte, que se caracteriza por insertarse en la realidad y registrar lo que ocurre, minimizando la edición y apostando a una comunicación más "transparente" del universo que se filma, está presente en las instancias en que Engler interactúa espontáneamente con la gente (el sindicato de cañeros en Bella Unión, un amigo de la juventud en Paysandú, la enfermera y la paciente del consultorio en el que se desempeña como médico en Upsala). Si bien existe un conflicto ético asociado con la práctica de esta modalidad, la que ha girado en torno al tema del tratamiento de los sujetos que se muestran, la potencial explotación de sus imágenes, el pedir el consentimiento o no de su participación, la intervención de un espacio privado que se transforma en objeto de valoración al volverlo público, El Círculo recurre a estas instancias para documentar un rasgo de carácter del protagonista signado por el compromiso de trabajo comunitario. En el caso de la reunión del sindicato de cañeros, por ejemplo, se ve a Engler describir en lenguaje simple y tono humilde su labor como investigador pionero de la enfermedad de Alzheimer en tanto la escena en que supervisa la realización de una tomografía computada en Suecia ilustra su compromiso con la medicina, lo que señala la coherencia ideológica, delineando otro círculo de índole simbólica entre el Engler de ayer y el de hoy.

Ciertas decisiones relacionadas con el modo de acercamiento de la cámara al sujeto que va a dar testimonio, aspecto que en este documental sólo se hace presente cuando se introduce a cada uno de los ex rehenes, revelan el estilo reflexivo, definido como la modalidad más auto-cuestionadora del medio mismo. Al llamar la atención del espectador sobre los artificios que hacen posible la construcción de la realidad que se nos muestra, el documental nos recuerda que dicha realidad excede y no es idéntica a la que estamos percibiendo. Debido a que esa incongruencia que constatamos a nivel visual es acompañada del discurso de los narradores en off, el objetivo de persuadir al espectador sobre la veracidad de lo que se cuenta queda sin embargo asegurada y el

Revista Iberoamericana, Vol. LXXXI, Núm. 251, Abril-Junio 2015, 435-447 ISSN 0034-9631 (Impreso)

ISSN 2154-4794 (Electrónico) 
artificio puede interpretarse a la luz de un subtema presente en el documental que es el de la fragmentación. Si la voz que explica la historia de los distintos sobrevivientes (y que es la propia) aparece inicialmente siempre disociada de la imagen (los hombres se ven a través de planos enteros que gradualmente se vuelven planos generales) es posible leer el recurso como metáfora de la fisura entre el pasado y el presente (víctima de ayer, ejemplo de resistencia del hoy). Esta fisura, que connota negativamente el trauma experimentado por todos los hombres que se muestran, es de índole bisémica, ya que el efecto con que culmina es que, gracias a la palabra, llegamos finalmente a combinar la imagen de los distintos sujetos con su historia y terminamos por quedar situados a una distancia que los y nos coloca en la misma dimensión que ellos.

Es el estilo participativo, finalmente, el que liga todas estas modalidades por cuanto la entrevista como forma tradicional de aquel es usada sistemáticamente para oír los diversos testimonios, reservando los primeros planos para Engler. Emparentado con la metodología de las ciencias sociales (que privilegia el trabajo de campo), el documental participativo, por definición, propicia la reflexión sobre "la ética y la política del encuentro" entre un sujeto poseedor de una cámara y uno carente de la misma (Nichols 116). La desigualdad de poder (entre el que es mostrado y el que muestra) puede resultar más o menos opacada dependiendo del carácter de la inmersión del cineasta en el universo que registra; en ese sentido, la entrevista se erige como una forma particular del encuentro social que permite expandir el punto de vista más allá del de aquel del documentalista (121). En el caso de El Círculo, este aspecto se maneja preservando la entrevista como mecanismo de inclusión de una perspectiva histórica (la de los que responden) sin incluir nunca a los cineastas en escena.

$\mathrm{Si}$ aceptamos que un aspecto central del potencial del género documental es persuadirnos a entender de cierta forma "cómo ha sido la realidad, cómo es en el presente y lo que puede llegar a ser" (Nichols 2), analizar la naturaleza de la interacción que se establece entre el documental y la realidad que éste se propone representar se vuelve central. Dicha interacción se manifiesta de tres modos: ofrece un retrato del mundo que resulta familiar (lo que establece su verosimilitud), canaliza los intereses de otros y finalmente, defiende un caso o una idea. Es posible así interpretar El Círculo a la luz de su función como documento de crimen de lesa humanidad, evidencia de aquello que no es deseable ni aceptable por la sociedad democrática actual. Esta constituye una causa en la que los intereses de la sociedad toda entran en juego y más aún en un momento en que como hemos mencionado el país se disponía a expedirse sobre la ley de Caducidad. El desafío central al que el proyecto se enfrenta entonces, es el de persuadir a su audiencia de que ese universo intangible, esencialmente ajeno como lo es el de la tortura vivida por Engler, tiene su base en el mismo universo familiar que la cámara recorre y a la que acompañamos. Una estrategia necesaria consistía entonces en reducir la distancia, geográfica y emocional, entre espectador y protagonista. Esta

Revista Iberoamericana, Vol. LXXXI, Núm. 251, Abril-Junio 2015, 435-447 ISSN 0034-9631 (Impreso)

ISSN 2154-4794 (Electrónico) 
distancia inicial se marca explícitamente con tomas de Engler y su mujer cenando y conversando en el espacio protegido de su casa mientras la cámara sólo atisba la escena a través del vidrio y se aleja al tiempo que las luces se apagan. El documental logra neutralizar o reducir la alteridad representada por el contexto sueco haciéndonos viajar junto a Engler hacia y por Uruguay. Es así que recorremos, situados a su lado, cuando cuenta sobre el pasado y detrás de él, cuando se reencuentra con el espacio de vejación. En esta interpretación del círculo como trayectoria vital de Engler (de Suecia a Uruguay y finalmente de regreso a Suecia pero también del hombre de mediana edad al joven de ayer e incluso al niño de antes) el espectador es invitado a reconstruir lo que es posible y a confrontar lo que no es. En ese sentido, las transiciones de tomas en negro entre lugares y testimonios le recuerdan al espectador, los límites de la identificación con el protagonista. Estos círculos diseñados metafóricamente a través de la película resultan subordinados a la versión literal del mismo. Su descripción se erige en eje de una de las dos secciones más extensas de la película en la que Engler, desde un primer plano, le habla al espectador sobre el mecanismo de resistencia al que atribuye su supervivencia:

Mi lucha es para frenar los pensamientos y apagar las voces entonces lo que hago es estar parado, empiezo a aprender a no pestañear para poder tener el punto ese y no perderlo. Entonces toda mi vida se empieza a concentrar en lo que yo le llamaba el circulito. Ponía un circulito en la pared y trataba de tener una imagen y dejarla pegada contra el circulito. Entonces agarro una imagen que es la imagen de mi casa cuando yo era niño que esa imagen me producía dolor, entonces digo: la voy a poner acá hasta que no me produzca ningún tipo de emoción y hasta que yo no tenga ninguna voz interna, mía, que me esté hablando. En esa lucha estuve cuatro años, día y noche porque lo único que me detenía era cuando me dormía. (El Círculo)

Pero ese símbolo de carácter cíclico-circular se propaga a otros episodios y sujetos. Hace visible el trauma que evidencian los dibujos mesiánicos hechos por Engler en la cárcel, preservados en cajas que guarda su hermana en Uruguay y por él en su casa de Suecia y sirve para unir a Engler con los ex rehenes que se hacen presentes en su testimonio sobre la común resistencia (Mauricio Rosencof, Julio Marenales, JorgeZabalza y José Mujica en Uruguay, Serrano Piedecasas desde España, pero luego reencontrado con Engler en Montevideo).

Otro círculo se establece entre Engler y Solari (ex soldado que aporta la visión del padecimiento desde su pasado de guardia de Engler), círculo éste que sugiere la deconstrucción de la estructura binaria víctima/victimario, con una cámara que al hacer un primer plano de los ojos del soldado en una foto del pasado procura sugestivamente una respuesta a la índole moral o psíquica del sujeto. La escena de la entrevista con Solari constituye la segunda más extensa y debido al espacio que se confiere al discurso del ex militar, el documental elabora sobre un ángulo usualmente ausente en los discursos

Revista Iberoamericana, Vol. LXXXI, Núm. 251, Abril-Junio 2015, 435-447 
de memoria dictatorial creados a partir de las víctimas. Si bien la narración de Solari expande la visión de un Engler debilitado física y emocionalmente, la autovaloración de su propio rol durante el tiempo en que fue su custodia ocupa un espacio prevalente culminando en una de las instancias más abiertamente emotivas presentes en el documental. La detallada descripción de la amistad forjada entre ambos así como el énfasis en las transgresiones en las que incurría Solari para reducir las restricciones impuestas sobre la relación carcelero-preso ofrecen al espectador una imagen particular de miembros del aparato represivo. Considerando la potencialidad de gestión mnemónica que tuvo y tiene el documental, hay que preguntarse de qué modo oficia esta historia en términos de ampliar los discursos del pasado en el país. Contrastando la entrevista presente en el filme y la versión expandida incluida en el libro se advierten detalles adicionales relevantes. El posicionamiento político de Solari en la escena mencionada es neutra, colocando la responsabilidad del no saber cómo evaluar la historia nacional de los 70 en un indefinido "ellos" que no les daba tiempo (a los soldados como él) a pensar. En el libro, sin embargo, Solari comenta sobre el impacto que tuvo en él y en otros el contacto con Engler: "Yo le debo a Henry un antes y un después en mi vida, porque si bien nunca hablamos de la cuestión de fondo, de a poco, él nos fue transmitiendo por qué estaba ahí. Si no hubiera sido por él, yo hubiera seguido como militar, hoy estaría por retirarme y, posiblemente, viviendo en la miseria. Así que él también fue importante para mí” (92).

Como mencionaba al inicio, Elizabeth Jelin ha demostrado que hablar de la configuración de una memoria social en sociedades posdictatoriales implica pensar en la memoria como trabajo. Analizar dicho proceso, por lo tanto, requiere tener en cuenta múltiples niveles relacionados con qué recuerdos se circulan y a quién pertenecen, la convergencia y divergencia entre la historia y la memoria, la noción de disputa como elemento clave a la hora de legitimizar o excluir discursos sobre el pasado así como incorporar, persuadiendo a las nuevas generaciones a discutir sobre los recuerdos preservados, compartidos con o negados a esas mismas generaciones. El Círculo se inserta en la red de discursos sobre el pasado uruguayo humanizando la figura de la víctima y de este modo generando la posibilidad de un acercamiento con el espectador. Si cristaliza el perfil de su protagonista en los términos en que la teoría anti-mimética auguraba la superación del trauma también problematiza la consideración de la figura del militar de un modo que tradicionalmente no se ve en las representaciones sobre los episodios del pasado uruguayo.

Una limitación notoria en la interpretación del terrorismo de Estado ha sido la derivada de evaluar lo ocurrido de acuerdo a la "teoría de los dos demonios", es decir, explicar la violencia dictatorial en términos de una oposición exclusiva entre la guerrilla y los militares. La reducción de la reflexión sobre el pasado en estos términos ha dificultado la discusión del tema a nivel nacional, estando muy presente incluso durante la campaña por el referéndum del 2009. El Círculo, si bien se centra en una historia

Revista Iberoamericana, Vol. LXXXI, Núm. 251, Abril-Junio 2015, 435-447 ISSN 0034-9631 (Impreso)

ISSN 2154-4794 (Electrónico) 
individual, no propone una personalización de la historia, sino que desplaza el eje de la discusión sobre el pasado, como lo hicieron enfáticamente los jóvenes encargados del diseño por la campaña del 2009, de lo político partidario a la dimensión amplia e inclusiva de los Derechos Humanos. ${ }^{11}$ En ese sentido, el discurso de Solari, que podría entenderse como un problemático símbolo de una controversial reconciliación adquiere otro valor. Expande la consideración de los hechos de violencia a sectores de la población tradicionalmente asumidos como un enemigo monolítico y con este gesto, el documental provoca un diálogo que amplía el coro de voces situadas a ambos lados de la confrontación ideológica. Si El Círculo se erige como una de las producciones destacadas de un año señalado como el del documental político en Uruguay (Ruffinelli 72), su índole política no se restringe a la filiación tupamara de su protagonista ni a la crónica de su militancia antes de su captura, sino que se formula fundamentalmente como invitación a juzgar lo experimentado por los presos políticos en términos concretos de violaciones a los Derechos Humanos.

\section{BiBLIOGRAFÍA}

Alzugarat, Alfredo. Trincheras de papel: dictadura y literatura carcelaria en Uruguay. Montevideo: Trilce, 2007.

Caetano, Gerardo y Hugo Achugar. 20 años de democracia. Montevideo: Taurus, 2005. Charlo, José Pedro, Aldo Garay y Virginia Martínez. El Círculo: las vidas de Henry Engler. Montevideo: Ediciones de la Banda Oriental, 2009.

El Círculo: las vidas de Henry Engler. José Pedro Charlo y aldo Garay, dirs. Montevideo:

Buen Cine Producciones, 2008.

Ferrario, Elbio. Entrevista personal. Agosto 2010.

Fourcade, Luis. De bigote p'arriba. Montevideo: Ediciones ORBE Libros, 2006.

González Baica, Soledad, Mariana Risso, y Lilián Celiberti. Las Laurencias: violencia sexual y de género en el terrorismo de estado uruguayo. Montevideo: Ediciones Trilce, 2012.

Jelin, Elizabeth, Judy Rein y Marcial Godoy-Anativia. State Repression and the Labors of Memory. Minneapolis: U of Minnesota P, 2003.

Leys, Ruth. Trauma: A Genealogy. Chicago: U of Chicago P, 2000.

11 Los spots publicitarios utilizados para la campaña televisiva enfatizaron una modalidad de convocatoria a la ciudadanía, sobre todo dirigida a los jóvenes "definidos como indefinidos", signada por el rechazo a la impunidad, no en términos de visiones políticas particulares sino por ser incongruente con la definición misma de una sociedad democrática. Se reiteraba asimismo la noción de que la definición de lo que constituye delito no depende de las circunstancias históricas y a través de analogías con crímenes cometidos en el presente y que conllevarían juicio penal, se apelaba al voto para juzgar los delitos del terrorismo de Estado.

Revista Iberoamericana, Vol. LXXXI, Núm. 251, Abril-Junio 2015, 435-447 ISSN 0034-9631 (Impreso)

ISSN 2154-4794 (Electrónico) 
Martin-Jones, David y María Soledad Montáñez. "Museums of Memory: The Recovery of Lost (National) Histories in the Uruguayan Documentaries Al pie del árbol blanco and El Círculo." Latin American Perspectives 40/1 (2013): 73-87.

Memorias de ocupación: violencia sexual contra mujeres detenidas durante la dictadura. Santiago: Fundación Instituto de la Mujer, 2005.

Nance, Kimberly A. Can Literature Promote Justice?: Trauma Narrative and Social Action in Latin American Testimonio. Nashville: Vanderbilt UP, 2006.

Nichols, Bill. Introduction to Documentary. Bloomington: Indiana UP, 2001.

Rodríguez, Álvaro. Los desastres de la cana. Montevideo: Orbe Libros, 2007.

Roniger, Luis, y Mario Sznajder. El legado de las violaciones de los derechos humanos en el Cono Sur. La Plata: Al Margen, 2005.

Ruiz, Marisa y Rafael Sanseviero. Las rehenas: historia oculta de once presas de la dictadura. Montevideo: Editorial Fin de Siglo, 2012.

Ruffinelli, Jorge. "Uruguay 2008: The Year of the Political Documentary." Latin American Perspectives 40/1 (2013): 60-72.

Scarry, Elaine. The Body in Pain: The Making and Unmaking of the World. Nueva York: Oxford UP, 1987.

Taylor, Diana. Disappearing Acts: Spectacles of Gender and Nationalism in Argentina's "Dirty War". Durham: Duke UP, 1997. 
